\title{
Assessing the disease burden of non- alcoholic fatty liver disease in the real world - big data and big numbers
}

\author{
Jörn M. Schattenberg ${ }^{1 *}$ (D) and Mattias Ekstedt ${ }^{2}$
}

Keywords: NAFLD, NASH, Epidemiology, Real-world data, Advanced fibrosis, Fib-4, Awareness, Hepatocellular carcinoma, Screening

\section{Background}

Non-alcoholic fatty liver disease (NAFLD) is a growing burden on European healthcare [1], with estimated annual healthcare costs of $€ 19$ billion EUR within the EU-5 region (France, Germany, Italy, Spain and the United Kingdom) [2]. In studies with long-term follow-up, excess mortality in people with NAFLD was shown to be dependent on the degree of underlying hepatic fibrosis [3]. Importantly, NAFLD also significantly impairs patients' quality of life [4]. The histological definition of both the presence of the inflammatory subtype of the disease, which is commonly called non-alcoholic steatohepatitis (NASH), and hepatic fibrosis, causes challenges for all epidemiological studies on the prevalence of the disease in Europe.

\section{Evidence from a real-world study}

In a recent article published in BMC Medicine, Alexander et al. [5] undertook an enormous effort to extract data from the European Medical Information Framework in the UK, Netherlands, Italy, and Spain. They analyzed data from the electronic medical records of more than 18 million European patients with codes for NAFLD and (in some countries) for NASH. The control cohort constituted matched cases with up to 100 non-NAFLD patients for each NAFLD/NASH case and took into account GP practice site, age, sex and healthcare utilization habits into account. This represents one of the most comprehensive and largest control populations; for instance, The Health

\footnotetext{
* Correspondence: joern.schattenberg@unimedizin-mainz.de

${ }^{1}$ Department of Medicine, University Medical Center of the Johannes

Gutenberg University, Mainz, Germany

Full list of author information is available at the end of the article
}

Information Network covers up to $6.2 \%$ of the patients cared for in UK-based GP practices.

The authors confirm established risk factors that are relevant for NALFD; namely type 2 diabetes, arterial hypertension and obesity [6]. Importantly, the study underlines the relevance of these risk factors in a nonreferral based, non-high risk population and expands available knowledge through this very large real-world dataset. The authors observed a hazard ratio for cirrhosis of 4.73 (95\% CI: 2.43-9.19) and 3.51 for hepatocellular carcinoma (95\% CI: 1.72-7.16), underlining the relevance of liver-related outcomes in patients with NAFLD. The incidences of these diagnoses were even higher when the surrogate score for the presence of advanced fibrosis (in this case Fibrosis-4 score [Fib-4]) was ranked as high-risk. While it is likely that a number of NAFLD/NASH cases were not coded in the available healthcare records, this large real-world study cohort highlights the contribution of diabetes as a strong and independent predictor of advanced liver disease and hepatocellular carcinoma, which is in line with previous data and recent data from the USA [7]. Interestingly, the median time between coding liver disease and cirrhosis was, in general, short, ranging between 0.5 and 2.9 years. This highlights shortcomings in the current practice aiming to identify patients with developing liver disease at an early stage.

Challenges and implications for clinical practice in NAFLD Considering all available data, including the confirmation arising from this study, the reality of liver disease in metabolically diseased patients is highlighted: diagnosis is made at a late stage. It can take a long time - even several years - to develop advanced liver disease, during 
which time preventative or even therapeutic approaches could be implemented. However, the fact that many patients are diagnosed at an advanced stage, means that they are prevented from modifying the risk factors responsible for driving the progression of liver disease. This must be highlighted, particularly to primary and secondary care providers. To achieve this, the scientific field urgently needs real-world data from unselected clinical cohorts that represent the disease spectrum of the general population. In the current study, $0.7 \%$ of included patients had a diagnosis of NAFLD/NASH; this should be interpreted in light of the $24 \%$ estimated global prevalence of NAFLD [8]. Therefore, this study evaluates not the tip of the iceberg, but the tip of the tip of the iceberg.

Although this cohort probably represents a selected subtype of NAFLD/NASH, this study gives us a real world insight into the low awareness of NAFLD/NASH in primary care. We also learn that having a code for NAFLD/NASH does not, in itself, significantly raise awareness of this disease. With the advent of medical therapies for the treatment of NAFLD [9], the minimalistic approach to this patient population will be likely to change. It should also be highlighted that, even in the absence of a liver-directed, specific therapy, NAFLD is an 'indicator disease', which identifies patients at risk of developing diabetes [10] or cardiovascular disease and complications [8].

\section{Conclusions}

In summary, this study, together with many others, has clearly established NAFLD/NASH - with its metabolic comorbidities - as a public health challenge. Now it is time to support patients, advocacy groups and specialists to raise awareness about this liver disease.

\section{Abbreviations}

NAFLD: Non-alcoholic fatty liver disease; NASH: Non-alcoholic steatohepatitis

\section{Acknowledgements}

Not applicable.

\section{Authors' contributions}

JMS and ME conceived and wrote the manuscript. Both authors read and approved the final version of the manuscript.

\section{Funding}

Not applicable.

Availability of data and materials

Not applicable.

Ethics approval and consent to participate

Not applicable.

\section{Consent for publication}

Not applicable.

\section{Competing interests}

The authors declare that they have no competing interests.

\section{Author details}

'Department of Medicine, University Medical Center of the Johannes Gutenberg University, Mainz, Germany. ${ }^{2}$ Division of Gastroenterology and Hepatology, Department of Medicine and Health Sciences, Linköping University, Linkoping, Sweden.

Received: 14 May 2019 Accepted: 3 June 2019

Published online: 04 July 2019

\section{References}

1. Estes C, Anstee QM, Arias-Loste MT, Bantel H, Bellentani S, Caballeria J, et al. Modeling NAFLD disease burden in China, France, Germany, Italy, Japan, Spain, United Kingdom, and United States for the period 2016-2030. J Hepatol. 2018;69(4):896-904.

2. Younossi ZM. Non-alcoholic fatty liver disease - a global public health perspective. J Hepatol. 2019;70(3):531-44.

3. Hagstrom H, Nasr P, Ekstedt M, Hammar U, Stål P, Hultcrantz R, et al. Fibrosis stage but not NASH predicts mortality and time to development of severe liver disease in biopsy-proven NAFLD. J Hepatol. 2017;67(6):1265-73.

4. Huber Y, Boyle M, Hallsworth K, Tiniakos D, Straub BK, Labenz C, et al. Health-related quality of life in non-alcoholic fatty liver disease associates with hepatic inflammation. Clin Gastroenterol Hepatol. 2018:S15423565(18)31392-31392.

5. Alexander $\mathrm{M}$, Loomis AK, van der Lei J, Duarte-Salles T, Prieto-Alhambra D, Ansell D, et al. Risks and clinical predictors of cirrhosis and hepatocellular carcinoma diagnoses in adults with diagnosed NAFLD: real-world study of 18 million patients in four European cohorts. BMC Med. 2019;17:95.

6. Labenz C, Huber Y, Kalliga E, Nagel M, Ruckes C, Straub BK, et al. Predictors of advanced fibrosis in non-cirrhotic non-alcoholic fatty liver disease in Germany. Aliment Pharmacol Ther. 2018;48(10):1109-16.

7. Kanwal F, Kramer JR, Mapakshi S, Natarajan Y, Chayanupatkul M, Richardson $\mathrm{PA}$, et al. Risk of hepatocellular cancer in patients with non-alcoholic fatty liver disease. Gastroenterology. 2018;155(6):1828-37 e1822.

8. Younossi Z, Anstee QM, Marietti M, Hardy T, Henry L, Eslam M, et al. Global burden of NAFLD and NASH: trends, predictions, risk factors and prevention. Nat Rev Gastroenterol Hepatol. 2018;15(1):11-20

9. Younossi Z, Ratziu V, Loomba R, Rinella M, Anstee QM, Goodman Z, Bedossa P, Geier A, Beckebaum S, Newsome P, et al. GS-06-Positive Results from REGENERATE: A Phase 3 International, Randomized, Placebo-Controlled Study Evaluating Obeticholic Acid Treatment for NASH. J Hepatol. 2019; 70(1):e5.

10. Chang Y, Jung HS, Yun KE, Cho J, Cho YK, Ryu S. Cohort study of nonalcoholic fatty liver disease, NAFLD fibrosis score, and the risk of incident diabetes in a Korean population. Am J Gastroenterol. 2013;108(12):1861-8.

\section{Publisher's Note}

Springer Nature remains neutral with regard to jurisdictional claims in published maps and institutional affiliations.
Ready to submit your research? Choose BMC and benefit from:

- fast, convenient online submission

- thorough peer review by experienced researchers in your field

- rapid publication on acceptance

- support for research data, including large and complex data types

- gold Open Access which fosters wider collaboration and increased citations

- maximum visibility for your research: over $100 \mathrm{M}$ website views per year

At $B M C$, research is always in progress.

Learn more biomedcentral.com/submissions 